to here differ entirely from all attempts at viewing new possibilities for a direct spiritual influence on material phenomena in the limitation set for the causal mode of description in the analysis of atomic phenomena. For example, when it has been suggested that the will might have as its field of activity the regulation of certain atomic processes within the organism, for which on the atomic theory only probability calculations may be set up, we are dealing with a view that is incompatible with the interpretation of the psychophysical parallelism here indicated. Indeed, from our point of view, the feeling of the freedom of the will must be considered as a trait peculiar to conscious life, the material parallel of which must be sought in organic functions, which permit neither a causal mechanical description nor a physical investigation sufficiently thorough-going for a well-defined application of the statistical laws of atomic mechanics. Without entering into metaphysical speculations, I may perhaps add that any analysis of the very concept of an explanation would, naturally, begin and end with a renunciation as to explaining our own conscious activity.
In conclusion, I wish to emphasise that in none of my remarks have I intended to express any kind of scepticism as to the future development of physical and biological sciences. Such scepticism would, indeed, be far from the mind of a physicist at a time when the very recognition of the limited character of our most fundamental concepts has resulted in such far-reaching developments of our science. Neither has the necessary renunciation as regards an explanation of life itself been a hindrance to the wonderful advances which have been made in recent times in all branches of biology and have, not least, proved so beneficial in the art of medicine. Even if we cannot make a sharp distinction on a physical basis between health and disease, there is, in particular, no room for scepticism as regards the solution of the important problems which occupy this Congress, as long as one does not leave the highroad of progress, that has been followed with so great success ever since the pioneer work of Finsen, and which has as its distinguishing mark the most intimate combination of the study of the medical effects of light treatment with the investigation of its physical aspects.

\title{
Food Storage at Low Temperature
}

COME of the problems involved in the preservation of food for transport and storage have been dis. cussed by Sir William Hardy in two recent lectures*. The abandonment of the earlier agricultural civilisation by many races for an urban culture required the transportation for long distances of foodstuffs destined for the peoples of the cities. Non-perishable foods such as oil, honey and grain required no special treatment; meat and fish, however, were preserved by drying or curing with salt, and root vegetables for winter use as jams made with honey. It was not until the eighteenth century that the growth of winter vegetables was developed and another hundred years passed before low temperature began to be employed to preserve perishable food in the fresh condition.

The modern period began about fifty years ago, when the first cargo of meat was successfully brought from Australia in the frozen condition. That was made possible by mechanical refrigeration, and, at first, research and invention were occupied in perfecting the machinery, the insulation and the design of cold stores, in wagons or in ships. The properties of the material to be stored were, on the whole, neglected until more recently, when the importance of defining the exact conditions under which the stored foodstuffs survived for the longest time was realised and the science of biological engineering became differentiated from mechanical engineering.

The heavily insulated rooms at the Low Temperature Research Station at Cambridge are cooled

* The Hurter memorial lecture before the Liverpool Section of the Society of Chemical Industry on November 18, 1932 (Chem. and Ind. 52,$45 ; 1933)$. The Sir William Trueman Wood lecture before the Royal Society of Arts on February $22,1933$. by pipe grids through which cold calcium chloride brine is pumped. The first approximation to the required temperature is arrived at by regulating the temperature and rate of flow of the brine. The fine adjustment is made by treating the chamber as an electrically controlled thermostat.

Stored foodstuffs undergo changes in cold storage, the nature of which must be fully understood if the food is to be stored at the optimum temperature and if the store is to function efficiently. Fruit, for example, is alive, consuming oxygen and giving off carbon dioxide and heat. The heat production is greater the higher the tem. perature and is also increased by disease, for example, fungus rot. A rise of temperature in the store thus sets up vicious circles, with shortening of the storage life of the fruit. In addition to removal of heat from the store, the engineering problems involve the maintenance therein of an atmosphere with a constant content of oxygen, carbon dioxide and water vapour.

A further complication arises from the fact that storage life also varies, under the same conditions, with the earlier history of the fruit. The following variables have been found to affect the storage life of apples: variety, rootstock and age of tree, maturity of fruit on tree, its size and position on the inflorescence, the soil, manuring and climate, and finally orchard sanitation.

The rate of output of carbon dioxide on storage varies with the temperature, but the curves at different temperatures all have the same shape. The output falls continuously while the apple is growing and maturing on the tree. It then rises for a short time after picking and again decreases 
during the remainder of storage life. The similarity of the curves of output at different temperatures suggests that it must be governed by one factor only. This may be the rate of diffusion of oxygen - not of carbonic acid because it diffuses so much more rapidly - or the semi-permeability of the skin of the fruit to the respiratory gases. During the earlier period of storage the apple is peculiarly susceptible to the injury of internal breakdown; during the later period it is only slightly susceptible to internal breakdown but increasingly liable to attack by fungi. For Bramley's Seedling it has been found that minimum wastage from both these factors occurs at $3^{\circ} \mathrm{C}$. which is therefore the optimum temperature for storage of this variety.

Another aspect which must be considered is the fact that apples give off vapours or emanations in minute amounts, which are poisonous to other fruit, one part in about fifty thousand being a toxic dose. The phenomenon has a commercial interest since the emanation tends to quicken the ripening of young apples, so that a colony of apples tends to ripen at the same time.

Meat and fish may be either chilled or frozen. Fruit, of course, unless intended for some secondary process such as jam-making, must not be frozen. Chilling will only delay the growth of moulds or bacteria long enough to give the material a storage life of about $30-40$ days. If it cannot be marketed within this time, it is necessary to freeze it. Freezing, however, alters the physical state of the tissues and yet does not abolish all chemical change. Moulds, for example, can grow down to $-7^{\circ} \mathrm{C}$. and bacteria down to $-3^{\circ} \mathrm{C}$. Freezing results in the separation of ice within the tissue. It acts therefore as a drying agent by withdrawing water. The proteins of musele become increasingly insoluble when meat is stored in the frozen state, so that on thawing the product is tough and unpalatable. The rate of change has been found to be greatest at about $-3^{\circ} \mathrm{C}$. The change is entirely due to freezing and does not occur when the tissue is merely overcooled to this or even a lower temperature.

Detailed study of the changes occurring in muscle in the cold has shown that overcooling to $-4^{\circ} \mathrm{C}$. does not prevent return to the normal state on thawing. Freezing at this temperature kills the muscle, which becomes opaque, shortened and acid due to the formation of lactic acid. This acid is produced and accumulates even in the frozen state, the rate of accumulation rising to a maximum at about $-2^{\circ} \mathrm{C}$. The temperature of $-1 \cdot 6^{\circ} \mathrm{C}$. is critical. When frozen at a higher temperature the muscle can get rid of the excess lactic acid and revert to normal on thawing. Muscles frozen at a lower temperature have lost this power; they are dead on thawing and the acid increases in them as in rigor mortis. Thus at $-1 \cdot 6^{\circ} \mathrm{C}$. the catalysts responsible for the re-synthesis of the lactic acid to glycogen are destroyed. It has also been found that the catalysts responsible for the synthesis of phosphagen are permanently lost at $-2 \cdot 5^{\circ} \mathrm{C}$. and those concerned in the oxidation of lactic acid at $-3 \cdot 2^{\circ} \mathrm{C}$.

In conclusion, Sir William Hardy referred to the difficulty of assessing the dietetic value of different foodstuffs. Experiments with human beings, which are costly and difficult, will no doubt give an answer in digestible calories which will be quite decisive, but there is little doubt that the answer in terms of human wellbeing will be indecisive. There are certain properties of foodstuffs, hard to define, which yet play their part in the assessment of the suitability of these foods for human consumption. 'Bloom' in meat is a case in point: it appears to have no obvious relation to digestibility, yet it is inadvisable to dismiss the judgment of the trade expert as devoid of physiological meaning. It is never safe to dismiss the tradition of the practical man as having no scientifie basis.

\section{Obituary}

\section{DR. H. O, Forbes}

$\mathrm{D}^{\mathrm{R}}$ $R$, HENRY OGG FORBES, who died at Selsey on October 27, 1932, was well known among travellers and naturalists in the latter part of the last century, but his activities had been for many years cut short by constant ill-health and consequent seclusion. The second son of the Rev. Alexander Forbes of Dunblade, Aberdeenshire, he was born on January 30, 1851, and educated at Aberdeen Grammar School and afterwards at the Universities of Aberdeen and Edinburgh. $\mathrm{He}$ proposed to enter the medical profession, but owing to the accidental loss of an eye, he abandoned this career, although he had almost completed the necessary examinations.

Forbes's earliest travels were in Portugal where he made biological and geological investigations; but in 1878 he embarked on an expedition to the
Far East where he spent five years wandering among the Dutch islands-Java, Sumatra, Banda, Amboina, Timor-Laut, Buru and Timor-making observations and collecting zoological and other material. After his return to England, he published in $\mathbf{1 8 8 5}$ his well-known volume: "A Naturalist'sWanderings in the Eastern Archipelago: a Narrative of Travel and Exploration from 1878 to 1883." Mrs. Anna Forbes wrote a book "Insulinde" (1887) giving her experiences of this expedition.

Forbes went to British New Guinea in 1885 and early in 1886 made an expedition inland from Port Moresby, hoping to ascend the Owen Stanley Range. Through no fault of his he was unsuccessful, but he made large botanical and other collections and entered into friendly relations with the Sogeri. Mr. John Douglas, the Administrator, 